\title{
Dietetics: The Unfinished Bridge
}

Debbie MacLellan and Jacqui Gingras, Co-Editors

Is there anyone on earth who has not felt disconnected or isolated since the Covid-19 pandemic began? Travel has been largely curtailed, supply chains disrupted, higher education has gone mostly online, and mental illness has become a major issue everywhere. For many, it feels like our bridge to the 'normal' world has broken. Despite the many issues that we have all faced over the past year, Critical Dietetics has published its first newsletter and the Journal continues to receive excellent submissions. We are pleased to offer eight of them and a book review to you in this issue. Although seemingly disparate in nature, they cover topics that need to be a part of the conversation in Critical Dietetics in order to make our profession stronger.

We begin with two urgently needed and welcomed articles that we are calling Insights. These articles make powerful statements about what the profession needs to do to insure Black Lives Matter. Now is not the time for incremental changes, so we encourage you to read and share these articles widely. They have been peer-reviewed and now need to inform dietetic policy at all levels including education, research, and practice. We thank the authors of this work for taking the time to clearly articulate what needs to be done. There is no excuse for inaction.

In the first of three reflexive writing pieces, Firth \& Morley discuss the need for ethical guidelines for research with transgender people and communities. In a second article, Morley and three student-colleagues describe the benefits of a more extensive way of teaching and learning nutrition assessment, going well beyond the ABCDs of which we are mostly familiar. Rose highlights the shifts in thinking from her time as an "obesity epidemic" entrepreneur and how Critical Dietetics was transformative.

In a compelling piece of art-based inquiry from his doctoral dissertation, Joy reminds us to attend to the movement, colour, and playfulness of the Queen of Hearts. How does this art make claims of diversity in dietetics? We welcome more and ongoing series of art-based work in our future issues.

There are three research articles in this issue. First, Burt explores the Mediterranean diet's rise to prominence from an historical perspective. Larkey, Quatromoni and Fuster studies dietitians' practice barriers to implementing intuitive eating and Health at Every Size in community settings. And, van Kesteren and Evans critically examine the role of cooking programs in reducing health inequalities in the UK.

Finally, Kostka offers a review of Feminist Food Studies, the long awaited contribution from Parker, Brady, Power, and Belyea (2019) that outlines so powerfully the need for an intersectional feminist analysis in food studies. When reading this book review think about how you might translate these concepts into your own dietetic practice. 
Of course, this is the first issue created as we bridge between editors. The work of co-editing has been purposeful and supportive. We have enjoyed this transition very much. Of course, none of what we strive to accomplish would be possible without the contributions from the reviewers and from Kerry Beake who creates such wonderful design and presents our work to our readers in a way that evokes such pride and passion.

Finally, we look forward to where the bridge leads, what pieces our forthcoming Special Issues offer our thinking and our practice, and of course, what the Journal becomes with renewed energy and resolve! 